\title{
DEVELOPMENT OF THE INSTRUMENTATION AND MODELING FOR HEAT TRANSFER CHARACTERISTICS IN CFBC
}

TO

\author{
U.S. DEPARTMENT OF ENERGY \\ NATIONAL ENERGY TECHNOLOGY LABORATORY \\ P.O. BOX 10940, MS 921-118 \\ PITTSBURGH, PA 15236-0940 \\ FOR \\ PROJECT NO.: DE-FG22-95MT95013 \\ BY \\ DR. SEONG W. LEE, PRINCIPAL INVESTIGATOR \\ MORGAN STATE UNIVERSITY \\ SCHOOL OF ENGINEERING \\ BALTIMORE, MD 21239 \\ (Phone) 443-885-3106
}

April 2000 


\begin{abstract}
This technical report summarizes the research conducted and results obtained during the period beginning October 1, 1999 to March 31, 2000.

Heat transfer characteristics study and experimental work were continued using the bench-scale CFB system with the heat transfer probe. A copper tube with thermocouples was used as the heat transfer probe which was convenient to measure the temperature changes at different locations of the bed.

The heat transfer coefficient at different locations of the heat transferring surface decreases along the slides down the heat transfer surface; its temperature increase, which reducing the temperature difference between the surface of the tube and the bulk of the bed.
\end{abstract}

The radial variation of heat transfer coefficients showed little increase in heat transfer coefficient near the wall. It is believed that a long heat-transferring surface is located in the core region; a boundary layer develops near the wall of the surface. This may cause clusters or streamers to form which slides down the surface. According to the results, heat transfer coefficients in the core region are not affected significantly by the location of the probe.

The wall conduction resistance was eliminated and heat transfer coefficients were measured and calculated at different locations along the bed height. Heat transfer coefficients near the wall area of the bed are decreased along with the length of the probe. Heat transfer coefficient was slightly dropped when the probe was moved from the wall area to the central area of the bed. 


\section{TABLE OF CONTENTS}

PAGE

ABSTRACT ii

\section{SECTION}

1. HEAT TRANSFER MECHANISMS AND THEORY $-1$

1.1 Experimental Results of Single -Pipe Heat Exchange and Discussion------ 5

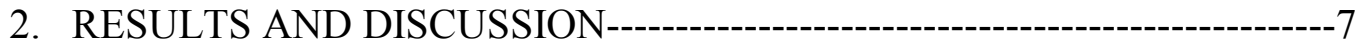

3. CONCLUSIONS ---

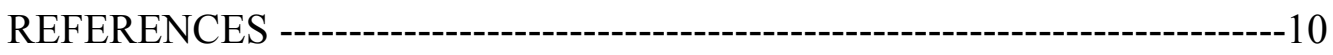




\section{SECTION 1}

\section{HEAT TRANSFER MECHANISMS AND THEORY}

The main column of a circulating fluidized bed consists of a core of uniformly dispersed solids which move up with the upflowing gas surrounded by a thin annulus where solid agglomerates or clusters move down. Therefore, the mechanism of bed to wall heat transfer in these two regions need to be studied separately. A heat transfer probe placed near the wall. The results indicated different heat transfer coefficients at different axial locations of the probe. Similarly, at a particular axial location of the probe, beat transfer coefficient changed as the probe is moved from the wall to the core region of the bed.

In the annulus, the wall of a heat-transferring surface usually comes into contact with clusters and dispersed phase. In the annulus region the heat transfer coefficient is dictated partly by clusters and partly by dispersed phase and is given by [1]

$$
\mathrm{h}=\mathrm{h}_{\mathrm{c}} \delta \mathrm{c}+(\mathrm{hd}+\mathrm{hg})\left(1-\delta_{\mathrm{c}}\right)
$$

The term $\left(h_{d}+h_{g}\right)$ is the contribution by dispersed phase which is discussed later. The fraction of wall area covered by clusters, $\delta_{\mathrm{c}}$ may be written as [2]

$$
\delta_{\mathrm{c}}=\mathrm{K}\left[\left(1-\varepsilon_{\mathrm{w}}-\mathrm{Y}\right) /\left(1-\varepsilon_{\mathrm{c}}\right)\right]^{0.5}
$$

In Equation (2) the voidage near the wall, $\mathcal{E}_{\mathrm{w}}$ is obtained from the following equation proposed by [3] after assuming $\mathrm{r} / \mathrm{R}$ equal to 1 .

$$
\varepsilon(r)=\varepsilon_{a v}^{\left[3.62(r / R)^{0.622}+1.191\right]}
$$

The volume fraction of the dispersed solids in the annulus, $\mathrm{Y}$ is assumed to be equal to the volume fraction of solids in the core. This is obtained by considering the coreannulus structure of the bed. 
Following equation [4], at a particular cross-section of the bed, the upward and downward flux are related as,

$$
\text { Gup- } \mathrm{Gdown}_{\mathrm{n}}=\mathrm{G}_{\mathrm{s}}
$$

The upward flux in the core region at any axial location is given by

$$
\text { Gup }-U_{\text {sc }}\left(1-\varepsilon_{\text {core }}\right) \rho_{\mathrm{s}}\left(\tau_{\mathrm{c}} / \mathrm{R}\right)^{2}
$$

Where $U_{s c}$ is the actual solid particle velocity in the core, $\varepsilon$ core is the core voidage and $\tau_{\mathrm{c}}$ is the radius of the core.

The upward solid particle velocity in the core is taken as,

$$
\mathrm{U}_{\mathrm{sc}}=\mathrm{Ugc}_{\mathrm{gc}}-\mathrm{U}_{\mathrm{t}}
$$

The downward flowing solid can be assumed to move at a velocity equal to the maximum falling velocity of clusters, $U_{m c}$. The downward flux can be calculated as

$$
\mathrm{G}_{\text {down }}=\left[1-(\tau \mathrm{c} / \mathrm{R})^{2}\right] \mathrm{P}_{\mathrm{s}}\left(1-\varepsilon_{\mathrm{w}}\right) \mathrm{Umc}
$$

Equations (4) to (7) may be rearranged to give the following equation of core voidage

$$
\varepsilon_{\text {core }}=1-\frac{G_{s}+\left[1-\left(r_{c} / R\right)^{2}\right] \rho_{s}\left(1-\varepsilon_{w}\right) U_{m c}}{\left.\rho_{s}\left(r_{c} / R\right)^{2}\left[U_{0} / \varepsilon_{\text {core }}\right)\left(R / r_{c}\right)^{2}-U_{m c}\right]}
$$

The average voidage at any axial location, $\varepsilon_{\mathrm{av}}$ can be correlated with the voidage in the core region $\varepsilon_{\text {core }}$ and voidage near the wall $\varepsilon_{\mathrm{w}}$, by

$$
\left(r_{c} / R\right)^{2}=\left(\varepsilon_{a v}-\varepsilon_{w}\right) /\left(\varepsilon_{\text {core }}-\varepsilon_{w}\right)
$$

Equation (8) and (9) are solved simultaneous to obtain $\varepsilon_{\text {core }}$ at any axial location of the bed.

By considering the transient heat conduction into the cluster the heat transfer coefficient $h_{c}$ is obtained from the following equation [1,2,3].

$$
h_{c}=\frac{1}{\left(d_{p} / 10 k_{g}\right)+\left(t_{c} \pi / 4 k_{c} c_{c} \rho_{c}\right)^{0.5}}
$$


The value of maximum cluster velocity, $\mathrm{U}_{\mathrm{mc}}$ was taken as $1.26 \mathrm{~m} / \mathrm{s}$ [5]. The heat transfer coefficient due to the dispersed phase is obtained from the equation of Wen and Miller [6]

$h_{d}=\left(k_{g} / d_{p}\right)\left(c_{s} / c_{g}\right)\left(\rho_{d i s} / \rho_{s}\right)^{0.3}\left(u_{t}^{2} / g d_{p}\right)^{0.21} P_{t}$

In the core region, the heat transfer coefficient will be given by the following equation

$h_{\text {core }}=h_{d}+h_{g}$

In the equation (12) the dispersed phase heat transfer coefficient, $\mathrm{h}_{\mathrm{d}}$ was calculated by using Equation (11). The values of $\varepsilon_{\text {core }}$ as obtained from Equations (8) and (9) was substituted when $0<\mathrm{r} / \mathrm{R}<0.75$, and $\varepsilon$ (r) from Equation (3) was substituted when $0.75<$ $\mathrm{r} / \mathrm{R}<1$.

\section{Notation:}

$\mathrm{Cs}, \mathrm{Cg}, \mathrm{Cc}$ Specific heat of solid, gas and cluster (kJ/kg.K)

dp $\quad$ Bed particle diameter $(\mathrm{m})$

Gs $\quad$ Net solid circulation rate $\left(\mathrm{kg} / \mathrm{m}^{2} . \mathrm{s}\right)$

h, hc,hd,hg Total heat transfer coefficient due to cluster, dispersed phase $/ \mathrm{gas} \quad\left(\mathrm{w} / \mathrm{m}^{2} . \mathrm{k}\right)$

$\mathrm{Kg}$, kc Conductivity of gas and cluster respectively (w/m.k)

$\mathrm{K} \quad$ Constant in Equation.

L Length of the probe from the top (m)

$r \quad$ Radius of the bed from the center (m)

$\mathrm{R} \quad$ Inner radius of the bed $(\mathrm{m})$

$\mathrm{U}_{\mathrm{gc}} \quad$ Gas velocity in the core region $(\mathrm{m} / \mathrm{s})$ 
$\mathrm{U}_{\mathrm{mc}} \quad$ Maximum falling velocity of the clusters $(\mathrm{m} / \mathrm{s})$

$\mathrm{U}_{\mathrm{o}} \quad$ Superficial gas velocity $(\mathrm{m} / \mathrm{s})$

$\mathrm{U}_{\mathrm{sc}} \quad$ Solid velocity in the core region $(\mathrm{m} / \mathrm{s})$

$\mathrm{U}_{\mathrm{t}} \quad$ Terminal velocity of the bed solids $(\mathrm{m} / \mathrm{s})$

$\mathrm{Y} \quad$ Volume fraction of dispersed solids in the annulus

$\delta_{\mathrm{c}} \quad$ Fraction of wall area covered by clusters

$\varepsilon_{\mathrm{av}}, \varepsilon_{\mathrm{c}}, \varepsilon_{\mathrm{w}}, \quad$ Average voidage, cluster voidage and voidage near the wall

$\varepsilon_{\text {core }} \quad$ Voidage in the core

$\rho_{\mathrm{s}}, \rho_{\mathrm{c}}, \quad$ Density of bed particles and cluster $\left(\mathrm{kg} / \mathrm{m}^{3}\right)$

$\rho_{\mathrm{g}}, \rho_{\text {dis }} \quad$ Density of gas and dispersed phase $\left(\mathrm{kg} / \mathrm{m}^{3}\right)$ 


\subsection{Heat Transfer Rate of Single -Pipe Heat Exchanger}

In order to understand the heat transfer in the single pipe, a simple experiment was conducted in the CFBC system with water flow in the single pipe.

The heat transfer rate of the single pipe heat exchanger was calculated from this equation.

$$
\begin{aligned}
& \mathrm{Q}=\mathrm{m} \mathrm{C}_{\mathrm{p}} \Delta \mathrm{T} \\
& \mathrm{Q}=\mathrm{mC}_{\mathrm{p}}\left(\mathrm{T}_{\mathrm{h}}, \mathrm{i} \check{\mathrm{u}}_{\mathrm{h}}, \text { out }\right) \quad(\mathrm{W})
\end{aligned}
$$

Where,

$\mathrm{M}=$ mass flow rate $(\mathrm{kg} / \mathrm{s})$

$\mathrm{C}_{\mathrm{p}}=$ specific heat at constant pressure $(\mathrm{J} / \mathrm{kg})$

$\Delta \mathrm{T}=$ temperature difference between the inlet and outlet pipe $\left({ }^{\circ} \mathrm{C}\right)$

Since the water flowrate was measured in gallon per minute (gpm), we need to convert it into $\mathrm{kg} / \mathrm{s}$ by multiplying with a conversion factor of $3.785 \times 10^{-3} \mathrm{~m}^{3} / 60$ second.

Since, $\mathrm{m}=\rho \mathrm{V}$

Where,

$$
\begin{aligned}
& \mathrm{P}=\text { Density of water }=1000 \mathrm{~kg} / \mathrm{m}^{3} \\
& \mathrm{~V}=\text { Volume of water displaced }\left(\mathrm{m}^{3}\right)
\end{aligned}
$$

The specific heat exchange capacity value was obtained from the property table using the mean temperature of the inlet and the outlet pipe of the water flow. Two readings of the temperature were recorded at each flow rate and the mean of these temperatures was used to calculate the rate of heat transfer. During the experiment, the chamber temperature was increased at the range of $100^{\circ} \mathrm{C}$ for all flow rates. 
The test results were shown in the Table 1 . It can be seen that the heat transfer rate from CFBC to water was increased when water flow rate increased. It can be seen that the heat transfer rate was increased rapidly with the increase of the water flow rate.

When water flow rate was increasing, the inside-tube water velocity increased. It can improve the heat transfer from water to the tube wall. The heat transfer rate between the CFBC fluidizing air and the tube wall shall be same as the heat transfer between water and the tube wall to maintain the heat balance. The maximum flow rate was about 1.7 gpm.

Table 1 Single Pipe Heat Exchange Heat Transfer Rate

\begin{tabular}{|c|c|c|c|c|c|c|}
\hline \multicolumn{2}{|c|}{$\begin{array}{c}\text { Mass flow rate } \\
(\mathrm{kg} / \mathrm{s})\end{array}$} & $\begin{array}{c}\text { Tinlet mean } \\
\left({ }^{\circ} \mathrm{C}\right)\end{array}$ & $\begin{array}{c}\text { Toutlet mean } \\
\left({ }^{\circ} \mathrm{C}\right)\end{array}$ & $\begin{array}{c}\text { Tmean } \\
\left({ }^{\circ} \mathrm{C}\right)\end{array}$ & $\begin{array}{l}\text { Specific } \\
\text { Heat } \\
(\mathrm{J} / \mathrm{kg})\end{array}$ & $\begin{array}{l}\text { Heat Transfer } \\
\text { Rate }(\mathrm{W})\end{array}$ \\
\hline 1 & 0.0631 & 61.45 & 61.15 & 61.3 & 4186 & 79.24098 \\
\hline 1.5 & 0.09465 & 52.85 & 51.15 & 52 & 4182 & 672.90471 \\
\hline 1.7 & 0.10727 & 48.8 & 46.6 & 47.7 & 4180 & 986.45492 \\
\hline
\end{tabular}




\section{SECTION 2}

\section{EXPERIMENTAL RESULTS AND DISCUSSION}

Heat transfer characteristics study and experimental work were continued using the bench-scale CFB system with the heat transfer probe [7].

Figure 1 shows axial variation of heat transfer coefficient along with the probe height. The voidge did not change over the length of the probe. The heat transfer coefficient at different locations of the heat transferring surface decreases along the slides down the heat transfer surface; its temperature increases, which reducing the temperature difference between the surface of the tube and the bulk of the bed. This may make the heat transfer coefficient stable beyond a certain length of the heat transfer tube.

Figure 1 Heat Transfer Coefficient Changes with the Probe Height

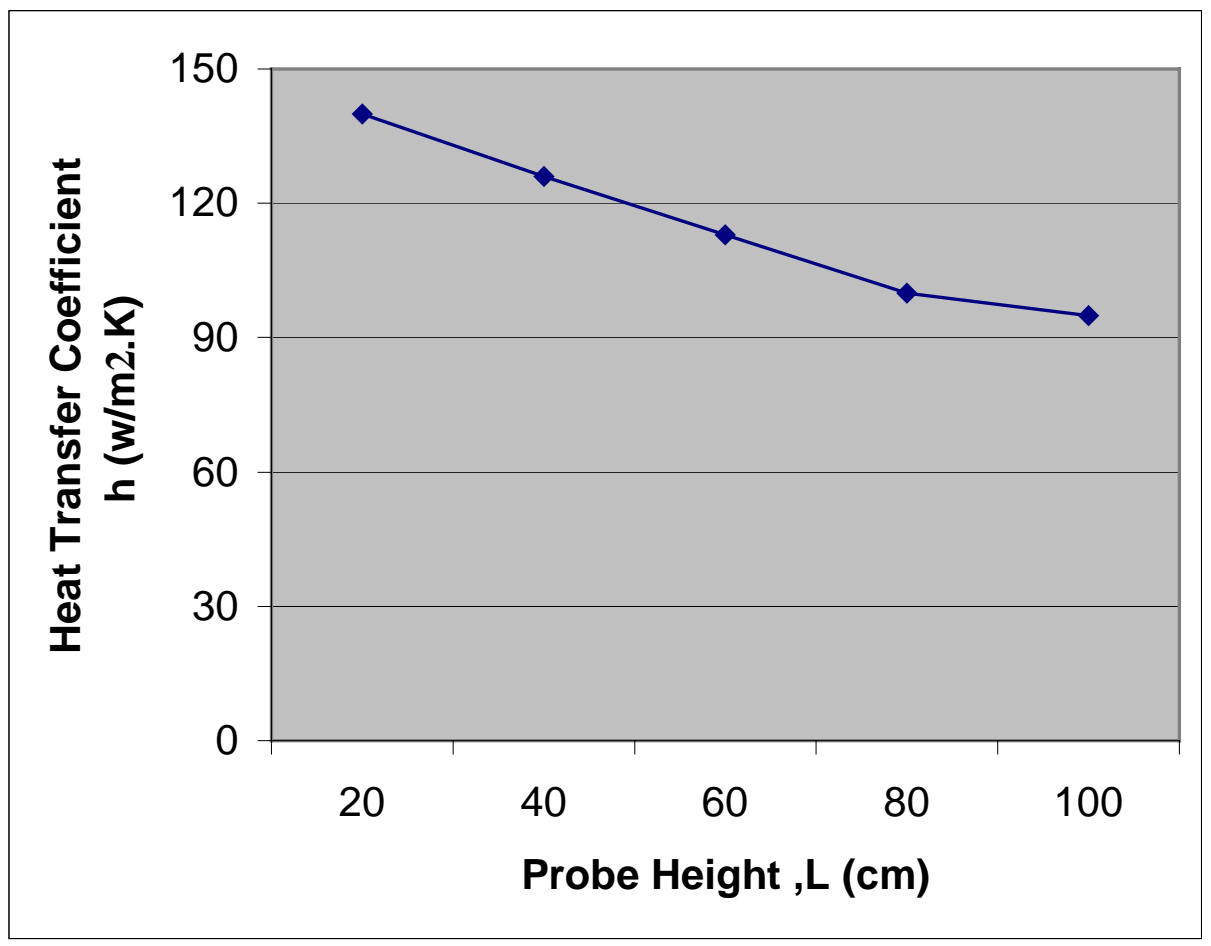


Figure 2 shows radial variation of heat transfer coefficients. The results show little increase in heat transfer coefficient near the wall. It is believed that a heat transfer surface is located in the core region; a boundary layer develops near the wall of the surface. This may cause clusters or streamers to form which slides down the surface. According to the results, heat transfer coefficients in the core region were not affected significantly by the location of the probe.

Figure 2 Heat Transfer Coefficient Changes with $\mathrm{r} / \mathrm{R}$

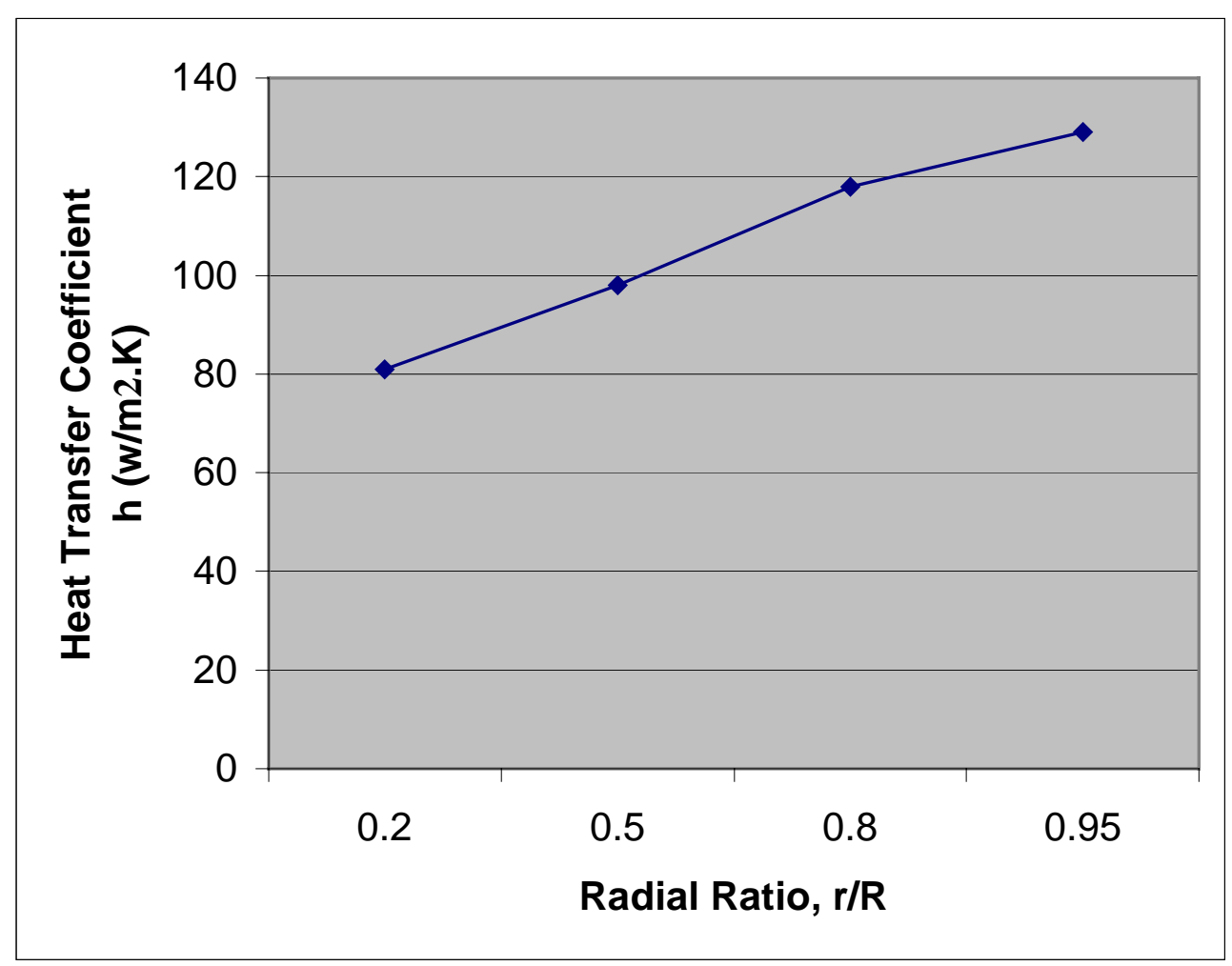




\section{SECTION 3}

\section{CONCLUSIONS}

A copper tube was used as the heat transfer probe which was convenient to measure the temperature changes at different locations using thermocouples. The wall conduction resistance was eliminated and heat transfer coefficients were measured and calculated at different locations along the bed height. Heat transfer coefficients near the wall area of the bed were decreased along with the length of the probe. Heat transfer coefficient was

slightly dropped when the probe was moved from the wall area to the central area of the bed. 


\section{REFERENCES}

[1] Basu P. and P.K. Nag, Int. J. Heat Mass transfer, 30, p 2399 (1987).

[2] Basu, p., Chem.Engn.Sci., 45, p3123 (1990)

[3] Tung, Y.,J.Li and M.Kwauk, "Radial Voidage Profile in a Fast Fluidized Bed" Fluidization'88, M. Kwank and D.Kunii(Ed)(1988).

[4] Ambler, P.A, B.J. Milne, F.Berruti, and D. S Scott, Chen.Eng.Sci., 45, p 2179 (1991).

[5] Wu, R.L., J.R.Grace and C.J.Lim.Chem.Eng.Sci., p 3389 (1990).

[6] Wen, C.Y. and E.N. Miller, Ind.Eng.Chem., 53, P.51 (1961).

[7] Lee, S.W., Technical Progress Report, No.6, U.S.DOE, Federal Energy Technology Center (FETC), October 1999. 